\section{Successful pediatric endoscopic submucosal dissection}
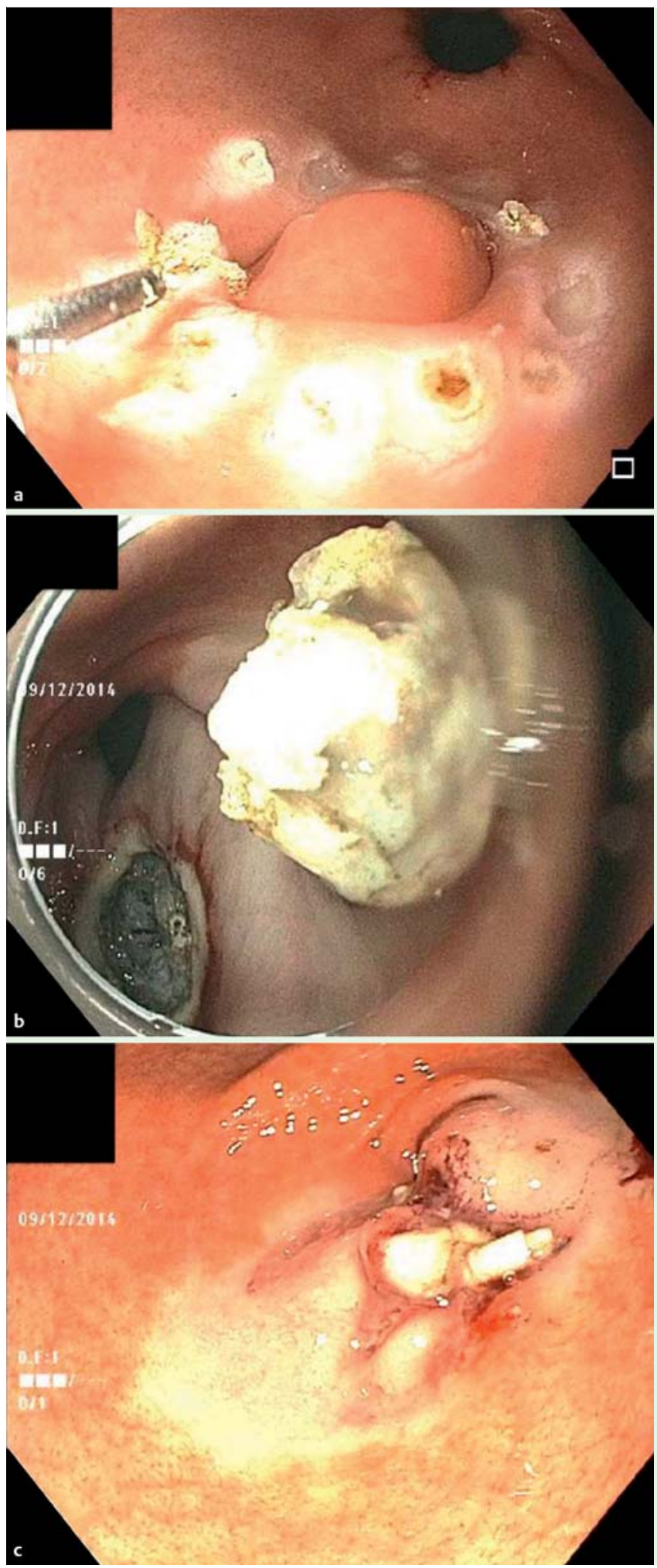

Fig. 1 Endoscopic views showing: a marks being made around the submucosal lesion using the multipurpose knife; $\boldsymbol{b}$ the resection site with the lesion fully excised; $\boldsymbol{c}$ the resection site following closure by endoscopic suturing.
Endoscopic submucosal dissection (ESD) is a minimally invasive option for the removal of submucosal lesions in the gastrointestinal tract $[1,2]$. ESD allows en bloc resection to be performed with the added ability to ensure adequate circumferential resection margins.

A 14-year-old boy presented with intermittent abdominal pain and vomiting. Upper gastrointestinal endoscopy revealed a $15-\mathrm{mm}$ antral submucosal lesion, which was hypothesized to be causing intermittent gastric outlet obstruction. An endoscopic ultrasound (EUS) was performed, which revealed the lesion to be arising from the submucosal layer without invasion into the muscularis mucosa. Evaluation with optical coherence tomography (OCT; NinePoint Medical, Bedford, Massachusetts, USA) confirmed that there was no evidence of muscular invasion.

The endoscope was inserted to the level of the lesion. A dissection knife (HybridKnife; ERBE, Marietta, Georgia, USA) was inserted through the endoscope and a border was marked circumferentially around the lesion ( Fig.1a). A mixture of a liquid starch solution, methylene blue, normal saline, and 1:10000 epinephrine was injected using high pressure around the edge of the lesion. Repeated submucosal injections and short bursts of needle-knife dissection were used to dissect the submucosal space below the lesion ( $\bullet$ Fig. $1 \mathbf{b}$ ). The final specimen was removed using a snare (Boston Scientific, Natick, Massachusetts, USA) and retrieved for pathology. The defect was sutured closed using an endoscopic suturing device (OverStitch;

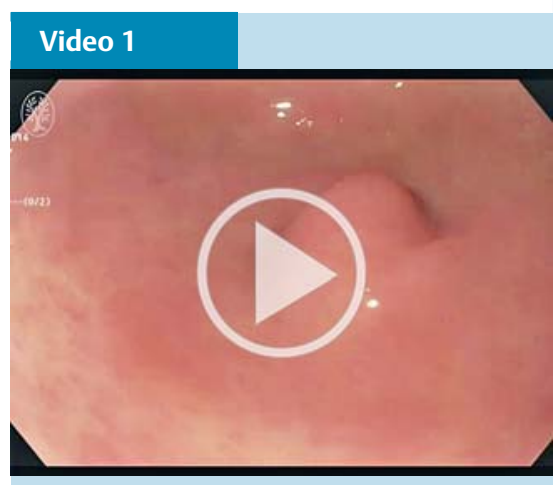

Endoscopic submucosal dissection (ESD) of a submucosal duplication cyst in the gastric antrum of a 14-year-old boy. The stages of the process are illustrated, finishing with closure of the defect using an endoscopic suture device. 
Apollo Endosurgery, Austin, Texas, USA) to prevent post-procedure bleeding ( $\bullet$ Fig. 1 c; $\odot$ Video 1).

Final histologic examination revealed a 3-mm duplication cyst within the deep submucosa, which had been fully excised. At 2 months, follow-up endoscopy showed a minimally visible scar at the site of the previous defect. The patient's nausea and vomiting had resolved, though he continued to experience intermittent abdominal pain that was thought to be unrelated.

Although now considered the standard of care for early gastric lesions [1,2], ESD is rarely described in children with only one other published case available in the literature [3]. Our experience demonstrates that ESD can be an efficacious therapeutic option for gastric lesions in the pediatric population.

\section{Endoscopy_UCTN_Code_TTT_1AO_2AG}

Competing interests: Michel Kahaleh MD has received grant support from Boston Scientific, Fujinon, EMcison, Xlumena Inc., W.L. Gore, MaunaKea, Apollo Endosurgery, Cook Endoscopy, ASPIRE Bariatrics, GI Dynamics, Olympus, NinePoint Medical, Merit Medical and MI Tech. He is a consultant for Boston Scientific, Xlumena Inc., Concordia Laboratories Inc. and MaunaKea Tech.

\section{Amy Tyberg, Melissa Rose, Aliza Solomon, Anna Nam, Michel Kahaleh}

Division of Gastroenterology and Hepatology, Weil Cornell Medical College, Cornell University New York, New York, USA

\section{References}

1 Gotoda T, Ho KY, Soetikno $R$ et al. Gastric ESD: current status and future directions of devices and training. Gastrointest Endosc Clin N Am 2014; 24: 213-233

2 Ono $H$, Yao K, Fujishiro $M$ et al. Guidelines for ESD and EMR for Early Gastric Cancer. Dig Endosc. Epub ahead of print 2015 Aug 1. DOI: $10.1111 /$ den. 12518

3 Jung EY, Choi SO, Cho KB et al. Successful endoscopic submucosal dissection of a giant polyp in a 21-month-old female. World J Gastroenterol 2014; 20: 323-325

\section{Bibliography}

Dol http://dx.doi.org/

10.1055/s-0034-1393592

Endoscopy 2015; 47: E621-E622

(c) Georg Thieme Verlag KG

Stuttgart · New York

ISSN 0013-726X

\section{Corresponding author \\ Michel Kahaleh, MD}

Division of Gastroenterology and Hepatology

Weill Cornell Medical College

New York

NY 10021

USA

Fax: +1-646-962-0110

mkahaleh@gmail.com 